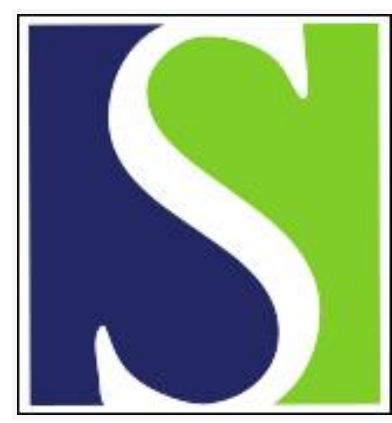

Scand J Work Environ Health 1997;23(5):364-369

https://doi.org/10.5271/sjweh.233

Issue date: Oct 1997

Occupational and personal risk factors for carpal tunnel syndrome in industrial workers

by Roquelaure Y, Mechali S, Dano C, Fanello S, Benetti F, Bureau D, Mariel J, Martin Y-H, Derriennic F, Penneau-Fontbonne D

The following articles refer to this text: 2009;35(1):19-36;

2009;35(5):342-348; 2013;39(5):495-505

Key terms: epidemiology; force; job-site analysis; MSD; musculoskeletal disorder; nerve entrapment; repetitiveness

This article in PubMed: www.ncbi.nlm.nih.gov/pubmed/9403467

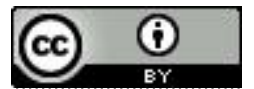




\title{
Occupational and personal risk factors for carpal tunnel syndrome in industrial workers
}

\author{
by Yves Roquelaure, $M D^{1}$, Sophie Mechali, $M D^{1}$, Corinne Dano, $M D^{1}$, Serge Fanello, $M D^{1}$, \\ France Benetti, MD2, Dominique Bureau, $M D^{2}$, Jean Mariel, MD2, Yves-Henri Martin, MD², \\ Francis Derriennic, $P h D^{3}$, Dominique Penneau-Fontbonne, $M D^{1}$
}

\author{
Roquelaure Y, Mechali S, Dano C, Fanello S, Benetti F, Bureau D, Mariel J, Martin Y-H, Derriennic F, Penneau- \\ Fontbonne D. Occupational and personal risk factors for carpal tunnel syndrome in industrial workers. Scand $J$ \\ Work Environ Health 1997;23(5):364-9.
}

\begin{abstract}
Objectives The purpose of the study was to evaluate both nonoccupational and occupational factors associated with carpal tunnel syndrome (CTS) in industrial workers.

Methods Sixty-five workers with CTS were compared with 65 referents matched for gender, age, and plant. The medical history and household activities of the workers and the ergonomic and organizational characteristics of the job were analyzed.

Results Exertion of force over $1 \mathrm{~kg}$ was associated with CTS [odds ratio (OR) 9.0]. Two risk factors were related to motion repetitiveness: length of the shortest elementary operation of $\leq 10 \mathrm{~s}(\mathrm{OR} 8.8)$ and lack of change in tasks or lack of breaks for at least $15 \%$ of the daily worktime (OR 6.0). No posture of the upper limb was associated with CTS. Workstation design involving the manual supply of the workers (OR 5.0) and the lack of job rotation (OR 6.3) were associated with CTS. The only personal factor associated with CTS was a parity of at least 3 (OR 3.2). There was a continuous increase in the odds ratio against the number of risk factors accumulated by the workers; the odds ratio thus ranged from 5.6 when 3 of the 6 risk factors were present to $\geq 90$ when 4,5 , or 6 risk factors were accumulated.

Conclusions The results were in agreement with a model for CTS which included 1 personal and 5 occupational risk factors. The number of risk factors cumulated by the workers seems to be a major determinant of CTS.
\end{abstract}

Key terms epidemiology, force, job-site analysis, musculoskeletal disorders, nerve entrapment, repetitiveness.

Carpal tunnel syndrome (CTS) is the most commonly reported nerve entrapment in both industrial (1) and nonindustrial populations (2, 3). Armstrong et al (4) had proposed a conceptual model for CTS which addressed its complex, multifactorial nature. Personal factors associated with CTS include female gender (2), gynecological status $(5,6)$, various medical conditions $(2,3,7,8)$, and individual factors such as wrist depth:width ratio (9), general physical condition (10), obesity (11), and smoking habits (5). Occupational risk factors for CTS include highly repetitive or forceful exertions of the hand and the wrist (12), repetitive or forceful pinching $(12,13)$, re- peated flexion or extension of the wrist (7), ulnar deviation of the wrist (4), segmental vibration (13), and mechanical stress on the base of the palm (2). Psychosocial stressors and work organizational factors have been associated with musculoskeletal disorders, although the exact nature of the relationship remains unclear (14).

The occurrence of many cases of CTS in 3 large plants in the area of Angers, in the west of France, initiated a case-referent study to examine the respective influence of medical history, nonvocational activities, and work conditions on the causation of the CTS factors in these industrial populations.

Département de Santé au Travail et d'Ergonomie [Department of Occupational Health and Ergonomics], Centre Hospitalier Universitaire [University Hospital], Angers Cedex, France.

2 Service Médical Interentreprises de 1'Anjou [Occupational Health Service of Anjou], Angers Cedex, France.

3 Institut National de la Santé et de la Recherche Médicale [National Institute of Health and Medical Research], Villejuif Cedex, France.

Reprint requests to: Dr Y Roquelaure, Département de Santé au Travail et d'Ergonomie, Centre Hospitalier Universitaire, 4 , rue Larrey, F-49033 Angers Cedex, France. 


\section{Subjects and methods}

This case-referent study was performed in 1993-1994 in 3 plants where television sets (plant A), shoes (plant B), and automobile brakes (plant C) were manufactured. Production-line work was common in these highly efficient manufacturing companies, which employed 1000, 600, and 650 wage earners, respectively.

\section{Subjects}

The medical files (which were filled out each year by the occupational physician of the company) of all the employees aged from 18 to 59 years were reviewed by 2 assessors. All blue-collar workers with a medical history of CTS between 1 January 1990 and 30 December 1992 were screened. The subjects who already had a long history of CTS or another musculoskeletal problem before 1990 were not accepted as cases since the pattern of determinants could have been obscured in the course of time. Subjects with malignancies, theumatic diseases, thyroid dysfunction, and diabetes before 1 January 1990 were also excluded. The case of CTS was included in the study if the medical files related at least 3 of the following conditions (12): (i) tingling, pain, or numbness in the median nerve distribution of the hand with nocturnal exacerbation with more than 20 occurrences or lasting more than 3 weeks in the previous year; (ii) a positive Tinel's sign and a positive Phalen's test or hypoesthesia in the territory of the median nerve; (iii) slowing of the sensory or motor conduction velocities $(<40 \mathrm{~m} / \mathrm{s})$ in the median nerve at the wrist level; and (iv) surgical release of the transverse carpal ligament.

All the electroneurographic studies were made with the same technical setup according to a standardized protocol. Electromyography was performed on the abductor pollicis brevis, first dorsal interosseous, flexor pollicis longus, flexor carpi radialis, and brachioradialis muscles. The median nerve was supramaximally stimulated at the elbow to measure the maximal motor nerve conduction velocity at forearm and wrist levels. The most symptomatic finger or the third digit was then stimulated with simultaneous recording from bipolar surface electrodes over the median nerve proximal to the carpal ligament with a distance of $6-8 \mathrm{~cm}$. Hand temperature was carefully controlled and kept above $28^{\circ} \mathrm{C}$. Abnormal electroneurographic findings were not required for inclusion in the study if the CTS has been treated surgically.

Altogether 65 workers [55 women, 10 men; mean age 41.1 (SD 7.5) years] who had been diagnosed as having CTS were included in the study. Twenty-four workers came from plant A, 24 from plant $B$, and 17 from plant $\mathrm{C}$. The CTS was unilateral in 52 workers (32 right, 20 left) and bilateral in 13. Fifty-five cases were surgically treated in the same hand surgery center, and the others had been treated with cortisone injections or physical therapy.

For each case worker, a referent was randomly selected from the blue-collar workers of the same gender and the same year of birth from the pay-roll rosters of the corresponding plant. The medical files of all the referents - which were filled out each year by the same occupational physician with the same methodology as for the case workers - were reviewed by the same 2 assessors. The referents had to be free of CTS and musculoskeletal disorders of the upper limb from 1984 to 1992. No nerve conduction studies were performed. The exclusion criteria were the same as those applied to the case workers. Sixty-five referents [55 women, 10 men; mean age 41.2 (SD 7.2) years] were included in the study.

The age and gender characteristics of the case workers and their referents were similar. There was no significant difference between the groups as far as number of children in household, education, and habitat were concerned, nor did their body mass index (weight/square height) differ significantly [case workers 24.2 (SD 4.1) $\mathrm{kg} / \mathrm{m}^{2}$ versus referents 24.5 (SD 4.9) $\mathrm{kg} / \mathrm{m}^{2}, \mathbf{P}=0.81$ ]. Obesity (BMI $>30)$ was not associated with CTS $(12.3 \%$ versus $15.4 \%, \mathrm{P}=0.61)$. The number of current smokers was not significantly higher in the case group $(P=0.24)$.

\section{Data collection}

Medical history. The medical history before the onset of CTS or the corresponding date of the matched referent was assessed by 2 assessors specializing in occupational health and ergonomics by screening the medical files of the selected workers. Information on weight, height, hand dominance, smoking habits, alcohol consumption, and use of painkillers, steroids and nonsteroidal antiinflammatory drugs for over 3 weeks - which was systematically included in the medical records - was studied. Information about pregnancy, natural menopause, gynecological surgery, and oral contraceptive use was also collected.

Nonoccupational activities. Using a self-administered questionnaire, we collected information on schooling, marital situation, habitat, household duties, sewing, knitting, odd jobs, gardening, music, and physical exercise.

Occupational activities. The workstation studied was the one occupied by the case workers 6 months before CTS was diagnosed. For the referents, it was the workstation occupied at the end of 1992.

The length of employment and the duration of previous manual work were calculated at the date of the diagnosis of CTS for the case workers and at the corresponding date for the matched referents. Previous work was considered to have been repetitive if the time cycle was 
under $30 \mathrm{~s}$; it was considered to have had high force if it required prehensive efforts of over $1 \mathrm{~kg}$.

Two specially trained assessors performed the jobsite work analysis by direct observation unaware of the medical status of the workers. They used the same checklist for the case workers and the referents. When the workers had two or more workstations, the analysis was performed on the workstation most often occupied. The job rotation between different workstations was recorded. The workstation information included the way in which parts were supplied to and forwarded from the workstation and also the number of parts produced. Also taken into account were the type of tools used, the nature of the materials, and the work pace and its possible alterations. The workers were questioned about their possibilities to choose the way the work was done ("freedom of action"). Exposure to cold and vibration was recorded. Motion repetitiveness and the segmental posture of the upper limb were evaluated for the most common daily task. A step-by-step description of the motions required to perform the job was carried out according to the "motion time" methods, as modified by Armstrong et al (15). The number of motions per time cycle and the length of the shortest elementary operation were calculated, and the average of 10 work cycles was used. Workhours and the duration of the main task, secondary tasks (such as preparatory work or quality control), and breaks were determined. The job was considered continuous when the duration of the breaks or the secondary tasks accounted for under $15 \%$ of the job duration (excluding meal breaks). A checklist based on the RULA method (16) was used to evaluate the angular position of the elbow (flexion $\leq 135^{\circ}$ ), forearm (pronosupination), and wrist (flexion $>45^{\circ}$, neutral, extension $>45^{\circ}$ ), the frequency of certain activities (pinching, gripping, screwing, pulling, pushing, lifting, turning), and the nature of the motion performed by the hand (precise, forceful). Hand-exerted forces were determined by the weight of the tools and the parts handled. Force was considered "high" when the load was greater than $1 \mathrm{~kg}$ with a frequency of exertion in excess of 10 times per hour.

\section{Analysis}

Matched odds ratios were calculated using McNemar's method to estimate the association between CTS and dichotomous exposure factors after adjustment for gender and age criteria. Quantitative data were analyzed by the paired Wilcoxon test. Multiple regression techniques were used to estimate associations between CTS and exposure with control for age (in 4 decade groups), gender, and plant. The data acquisition was done on Epi-info 5.0 software and the statistical package for the social sciences (SPSS for Windows version 6.1).

\section{Results}

\section{Medical history}

Regarding women's gynecological history, no association was found between CTS on the one hand and hysterectomy $(P=0.72)$, ovariectomy $(P=1.00)$, menopause $(P=0.48)$, or the use of oral contraceptives $(P=0.34)$ on the other. The parity of women in the case group [1.6 (SD 1.0)] was similar to that in the reference group [1.6 (SD 1.2)]. There were, however, significantly more often $(\mathrm{P}<0.001)$ more than 3 children born to women in the case group.

\section{Nonoccupational exposure}

The following results were obtained from the questionnaire. The average weekly duration of household chores was similar in both groups [8.4 (SD 6.1) hours versus 8.3 (SD 5.8) hours, $P=0.92]$. In both groups, a large number of children involved longer weekly household chores than for mothers with fewer than 3 children [10.8 (SD 5.9) hours versus 7.8 (SD 5.9) hours, $\mathrm{P}<0.03$ ]. Over 1 hour of household chores per day was not associated with CTS $(73.8 \%$ versus $69.2 \%, P=0.73)$. There was no difference concerning odd jobs $(\mathrm{P}=0.83)$, gardening $(\mathrm{P}=0.66)$, or sports $(\mathrm{P}=0.26)$.

\section{Occupational exposure}

Corporate seniority was similar in both groups [19.2 (SD 7.5) years versus $17.5(\mathrm{SD} 7.1$ ) years $\mathrm{P}=0.33$ ], nor did the duration of exposure to repetitive work differ significantly between the groups ( $\mathrm{P}=0.36$ ). The average seniority on the same workstation was high for both groups [8.5 (SD 8.2) years versus 10.0 (SD 8.0) years, $P=0.24$ ]. Daily worktime was also similar (ie, 7.5 hours). In addition, there was no difference in the average number of breaks and the total average length of breaks during the day.

A logistic model was constructed including age, gender, plant, household chores ( $>1 \mathrm{~h} /$ day), and all the dichotomous exposure factors and personal factors significantly associated with CTS with a P-value below 0.20 . The logistic model (table 1) displayed 6 risk factors. Exertion of effort - determined by the weight of the tools or the parts handled - of $1 \mathrm{~kg}$ was associated with the highest odds ratio [odds ratio (OR) 9.0]. Eight case workers and no referents exerted effort of $\geq 2 \mathrm{~kg}$. Two risk factors were related to motion repetitiveness, length of the shortest elementary operation of $\leq 10 \mathrm{~s}$ (OR 8.8), and lack of change in task or breaks for at least $15 \%$ of the daily worktime, excluding breaks for meals (OR 6.0). Cycle time or $<30 \mathrm{~s}$ was not associated with CTS $(\mathrm{P}=0.36)$.

The model displayed two other work-related factors. One concerned workstation design with manual supply 
Table 1. Risk factors for carpal tunnel syndrome in the final logistic model. (OR $=$ odds ratio, $95 \% \mathrm{Cl}=95 \%$ confidence interval)

\begin{tabular}{|c|c|c|c|c|c|c|c|}
\hline \multirow[t]{2}{*}{ Factors $^{a}$} & \multicolumn{2}{|c|}{ Case group } & \multicolumn{2}{|c|}{ Reference group } & \multirow[t]{2}{*}{ OR } & \multirow[t]{2}{*}{$95 \% \mathrm{Cl}$} & \multirow[t]{2}{*}{$P$-value } \\
\hline & $N$ & $\%$ & N & $\%$ & & & \\
\hline Force $>1 \mathrm{~kg}$ & 26 & 40.0 & 8 & 12.3 & 9.0 & $2.4-33.4$ & 0.001 \\
\hline Elementary operation $\leq 10 \mathrm{~s}$ & 62 & 95.4 & 54 & 83.1 & 8.8 & $1.8-44.4$ & 0.008 \\
\hline $\begin{array}{l}\text { Changes in activity or breaks } \\
<15 \% \text { daily worktime }\end{array}$ & 58 & 89.2 & 44 & 67.7 & 6.0 & $1.8-20.2$ & 0.004 \\
\hline No job rotation & 49 & 75.4 & 37 & 56.9 & 6.3 & $2.1-19.3$ & 0.002 \\
\hline Manual workstation supply & 27 & 41.5 & 16 & 24.6 & 5.0 & $2.2-21.2$ & 0.001 \\
\hline Parity $\geq 3^{\circ}$ & 18 & $32.7^{\mathrm{d}}$ & 5 & $9.1^{d}$ & 3.2 & $1.6-6.4$ & 0.001 \\
\hline
\end{tabular}

a Dichotomous factors. The reference is alternative.

b $-2 \log L R=117.516$; goodness of fit $=144.293, \mathrm{ddl}=6$.

C Zero for men, -1 for women whose parity was $<3$ and +1 for women whose parity was $\geq 3$

Women only (total out of 55).

by the workers (OR 5.0), and the other was the lack of job rotation between different workstations (OR 6.3). Screwing was more frequent in the case group (27.7\%) than in the reference group (12.3\%), but the difference was not statistically significant $(P=0.07)$. The model did not exhibit any other posture of the wrist, elbow, or the trunk or other specific motion of the hand in association with CTS.

After adjustment for all the factors entered into the logistic model, only 1 personal factor was associated with CTS, namely, parity of $\geq 3$ (OR 3.2). No interaction was found between parity and the 5 other factors in the logistic model.

The studied workers were categorized according to the number of risk factors displayed when the 6 key factors were included in the logistic model. As shown in table 2 , there was a monotonic increase in the odds ratios against the number of risk factors cumulated by the workers; the odds ratios thus ranged from 5.6 when 3 of the 6 risk factors were present to 90.0 or more when 4,5 , or all 6 risk factors were cumulated.

\section{Discussion}

The cases included in the study were severe CTS syndromes, as most of the workers had undergone surgery. The vast majority of the case workers had resumed work on the same workstation after surgery or medical treatment. This situation is similar to what Adams et al (17) reported, as it was due not only to the success of the surgery, but also to the fact that it was impossible to offer the workers less stressful jobs in their companies.

The main biomechanical risk factor identified was the high level of prehension forces. The threshold chosen as high was merely $1 \mathrm{~kg}$ because very few of the workers exerted effort in excess of 4 or even $2 \mathrm{~kg}$. The employees assembled brakes, television sets, or shoes, and the work called for precise motion and pinching rather than full-
Table 2. Number of risk factors accumulated by each worker. Each worker could display from 0 to 6 of the following risk factors: parity $\geq 3$, manual workstation supply, no operator turnover, force $>1 \mathrm{~kg}$, changes in activity or breaks $<15 \%$ daily worktime, elementary operation $\leq 10 \mathrm{~s}$. (OR $=$ odds ratio, $95 \% \mathrm{Cl}=95 \%$ confidence interval)

\begin{tabular}{lrrrrrrrr}
\hline $\begin{array}{l}\text { Number of } \\
\text { risk factors }\end{array}$ & \multicolumn{2}{c}{$\begin{array}{c}\text { Case } \\
\text { group }\end{array}$} & & \multicolumn{2}{c}{$\begin{array}{c}\text { Reference } \\
\text { group }\end{array}$} & OR & $95 \% \mathrm{Cl}$ \\
\cline { 2 - 3 } & $\mathrm{N}$ & $\%$ & & $\mathrm{~N}$ & $\%$ & & \\
\hline$\leq 2$ & 4 & 6.1 & & 30 & 46.2 & & 1.0 & $0.1-5.9$ \\
3 & 24 & 36.9 & & 32 & 49.2 & & 5.6 & $1.6-24.5$ \\
4 & 25 & 38.5 & & 2 & 3.1 & 93.7 & $13.4-93.8$ \\
$\geq 5$ & 12 & 18.5 & & 1 & 1.5 & 90.0 & $8.0-366.5$ \\
\hline
\end{tabular}

hand grasping. The muscle masses involved in such fine prehension are low, and a 1-kg effort can be considered significant (18). On the other hand, efforts such as squeezing or pressing were underestimated. Electromyography would probably display much higher force peaks.

Cycle time is an overall measurement of repetitiveness which considers neither the diversity of motion nor the interruption of motion activity in the work cycle. Consequently, this study defined repetitiveness of motion using 3 other variables that reflect various components of repetitive work, namely, the number of elementary operations per work cycle (motion diversity), the lack of breaks or changes in activity during the day (continuousness), and the duration of the shortest elementary operation (work cadence). Contrary to the results of previous studies (12), cycle time under $30 \mathrm{~s}$ was not associated with CTS. But the relation between CTS and exposure to cycle time under 1 minute was nearly significant in the logistic model. The diversity of the elementary operations was not a risk factor, apart from the brevity of the elementary operations.

No specific limb posture was clearly identified as a risk factor, a fact which has already been observed in several epidemiologic surveys using observation checklists (19). 
The study suggests that the manual supplying of materials to workstations is a risk factor for CTS. This finding differs from our initial assumption whereby workstation supply by automation meant an increase in time constraint. On the contrary, it seems that the biomechanical stress applied to the upper limb due to repeated manual supply is a more significant risk than the increase in time constraint due to workstation supply by automation. It would be worthwhile to confirm the significance of this factor in other companies because it could be due to specific organizational patterns in the 3 plants studied. Other features, such as work on mobile objects, are probably consequential, but they could not be pointed out due to the overlapping of the case workers and the referents.

The lack of job rotation was associated with the onset of CTS. The lack of turnover between different workstations may be partly explained by the fact that it was impossible to offer the case workers less stressful jobs in their companies before surgical treatment. On the other hand, given the substantial workstation seniority, a biomechanical explanation is more probable. When workers do not change workstations, biomechanical stresses are constantly applied to the same areas, which can entail chronic tissue lesions. Changing workstations makes it possible to change the application point of mechanical stress, which allows tissues to recover. The findings open up avenues for CTS prevention. It is likely that changing activities or taking breaks during the day plays the same preventive role as changing operator. The study does not demonstrate the influence of the duration or distribution of breaks, but the clear association between CTS and the lack of change in activities or of breaks less than $15 \%$ of the work time suggests that breaks play a major role in preventing CTS.

Contrary to what was observed among American blue-collar workers $(10,11)$, obesity was not associated with CTS in the industrial population examined. Unlike the findings of several studies $(5,8)$, gynecological history was not stressed. The only personal factor identified was high parity for women. Pregnancy is well established as a major risk factor for CTS (2) due to the endocrinous modifications and edematous syndrome it involves. Although clinical signs disappear after child birth in most cases, the literature features a report of a clinical series of CTS that appeared during pregnancy and led to clinical signs several years after delivery (6). But given the average age of the women in this study and the time elapsed since their last child birth - CTS relapse is unlikely. Having a large number of children can be a risk factor for CTS due to the increase in household chores, and we also found a higher risk for mothers of 3 or more children. Yet parity remained a risk factor significantly associated with CTS when household chores were taken into consideration in the logistic model. The association between CTS and parity is therefore prob- ably not due to increased household chores only. Endocrinous modifications due to repeated pregnancies may be noteworthy (6). Though often pointed out, other domestic and recreational activities were not connected with the onset of CTS. Psychological factors and stress were not addressed due to the retrospective nature of the data collection.

The CTS model produced was a multifactorial model with 5 occupational factors and 1 personal factor. Risk distribution between the case workers and referents pointed to the importance of the cumulating factors for the case workers since there was a monotonic increase in the odds ratio with the number of risk factors cumulated by the workers. These findings confirm studies that demonstrate the cumulative effect of risk factors $(12,13)$. And due to the probable multiplying effect between risk factors, radically eliminating 1 or 2 is probably more effective than mildly reducing them all. Depending on production requirements and technical organization, it might be easier to reduce force in certain situations or to minimize repetitiveness in others. In any event, jobs should be expanded or operators should be encouraged to move from one workstation to another so as to undergo different kinds of mechanical stress. This type of job organization should be done in a participative approach to diminish the risk of psychosocial stress.

In conclusion, the key CTS risk factors in an industrial setting are occupational. The logistic model featured 1 personal and 5 occupational factors. Risk factors displayed a cumulative effect and CTS likelihood increased sharply when the number of risk factors rose from 3 to 4 or more. The prevention of CTS in the workplace can be achieved by participatory ergonomics. Minimizing effort and the repetitiveness of motion generally means job enrichment. Operators should be encouraged to move from one workstation to another so as to undergo a vatiety of stress. Though overlooked by design engineers, workstation supply should be taken into consideration in the prevention of CTS. Prevention also calls for employee involvement and information about CTS risks and knowledge of the key ergonomic measures that could be taken (9)

\section{Acknowledgments}

This study was funded by the French Ministry of Research and Technology (grant 92-D-094), which is gratefully acknowledged.

Thanks are due to Dr G Raimbeau, MD, of the Angers Hand Surgery Center for his clinical advice and his support in the collection of the clinical data and to $\mathrm{Mr}$ A Benetti of Idéactive for his help in designing the checklist for work conditions. Thanks also go to Ms A Leclerc 
(Institut National de la Santé et de la Recherche Médicale, unité 88) for her valuable comments on the manuscript.

\section{References}

1. Hagberg M, Morgenstern H, Kelsh M. Impact of occupations and job tasks on the prevalence of carpal tunnel syndrome. Scand J Work Environ Health 1992;18:337-45.

2. Phalen $G$. The carpal tumnel syndrome: seventeen years experience in diagnosis and treatment of 654 hands. J Bone Joint Surg 1966;48 A:211-8.

3. Stevens JC, Beard CM, O'Fallon WM, Kurland LT. Conditions associated with carpal tunnel syndrome. Mayo Clin Proc 1992;67:541-8.

4. Armstrong TJ, Buckle P, Fine LJ, Hagberg M, Jonsson B, Kilbom A, et al. A conceptual model for work-related neck and upper-limb disorders. Scand J Work Environ Health 1993; 19:73-84.

5. Vessey MP, Villard-Mackintosh L, Yeates D. Epidemiology of carpal tunnel syndrome in women of childbearing age: findings in a large cohort study. Int J Epidemiol 1990;19: $655-9$.

6. Al Quattam MM, Manktelow RT, Bowen CVA. Pregnancyinduced carpal tunnel syndrome requiring surgical release longer than 2 years after delivery. Obstet Gynecol 1994;84: $249-51$.

7. de Krom MCTFM, Kester ADM, Knipschild PG, Spaans F. Risk factors for carpal tunnel syndrome. Am J Epidemiol 1990;132:1102-10.

8. Cannon LJ, Bernacki EJ, Walter SD. Personal and occupational factors associated with carpal tunnel syndrome. J Occup Med 1981;23:255-8.

9. Hagberg M, Silverstein B, Wells R, Smith R, Hendrick HW,
Carayon P, et al, editors. LATR. Les lésions attribuables au travail répétitifs: ouvrage de référence sur les lésions musculosquelettiques liées au travail. Paris: Maloine-IRSST, 1995.510

10. Nathan PA, Keniston RC. Carpal tumnel syndrome and its relation to general physical condition. Hand Clin 1993;9:253 61.

11. Werner RA, Albers JW, Franzblau A, Armstrong TJ. The relationship between body mass index and the diagnosis of carpal tunnel syndrome. Muscle Nerve 1994;17:632—6.

12. Silverstein BA, Fine LJ, Armstrong TJ. Occupational factors and carpal tunnel syndrome. Am J Ind Med 1987;11:343-58.

13. Wieslander G, Norback D, Gothe CJ, Juhlin L. Carpal tunnel syndrome and exposure to vibration, repetitive movement and heavy manual work. Br J Ind Med 1989;46:43 - 7.

14. Bongers PM, de Winter CR, Kompier MAJ, Hildebrandt VH. Psychosocial factors at work and musculoskeletal disease. Scand J Work Environ Health 1993;19:297-312.

15. Armstrong TJ, Radwin RG, Hansen DJ, Kennedy KW. Repetitive trauma disorders: job evaluation and design. Hum Factors $1986 ; 28: 325-36$.

16. Mc Atamney L, Corlett EN. RULA: a survey method for the investigation of work-related upper limb disorders. Appl Ergon 1993;24:91-9.

17. Adams ML, Franklin GM, Barnhart S. Outcome of carpal tunnel syndrome surgery in Washington state workers' compensation. Am J Ind Med 1994;25:527-36.

18. Stetson DS, Keyserling WM, Silverstein BA, Armstrong TJ, Leonard JA. Observational analysis of the hand and wrist: a pilot study. Appl Occup Environ Hyg 1991;6:927 - 37.

19. Kilbom $\AA$. Assessment of physical exposure in relation to work-related musculoskeletal disorders - what information can be obtained from systematic observations? Scand J Work Environ Health 1994;20 special issue:30-45.

Received for publication: 22 April 1996 